\title{
COMPARAÇÃO DA DIVERSIDADE TAXONÔMICA DE CARANGUEJOS ERMITÕES (ANOMURA: PAGUROIDEA) EM DOIS PERÍODOS COM INTERVALO DE 20 ANOS
}

\author{
Rodrigues, G.F.B. ${ }^{1,}$; Teles, J.N. ${ }^{1}$; Bernardes, V.P. ${ }^{1}$; Martins, F.K. ${ }^{1}$; Bernardo, C. H. ${ }^{1}$; Godoy, A.T. ${ }^{1}$ \\ \& Sousa, A.N. ${ }^{1}$ \\ ${ }^{1}$ Universidade Estadual Paulista "Júlio de Mesquita Filho" (UNESP), Campus Botucatu, Departamento de Zoologia, \\ NEBECC - Núcleo de Estudos em Biologia, Ecologia e Cultivo de Crustáceos. \\ *Autor correspondente: gabriel_rod94@hotmail.com
}

\begin{abstract}
Os índices de diversidade $(\Delta)$ e distinção $\left(\Delta^{+}\right)$taxonômica incorporam relações filogenéticas das espécies. A premissa principal dessas medidas é que a diversidade é maior em uma comunidade em que as espécies são filogeneticamente mais distintas. Dessa forma o objetivo do presente estudo foi utilizar a assembleia de ermitões como modelo para comparar os índices de diversidade alfa $\left(\mathrm{H}^{\prime}, \Delta \mathrm{e} \Delta^{+}\right)$de dois períodos distintos. Os ermitões (Paguroidea) foram coletados utilizando um barco de pesca equipados com redes do tipo doublerig, na Enseada de Ubatuba, litoral norte paulista. As amostragens foram realizadas, mensalmente, em dois períodos: primeiro período (09/1995 - 08/1996) e, segundo período (09/2016 - 08/2017). O índice $\Delta$ leva em conta a abundância das espécies enquanto que o $\Delta^{+}$é baseado somente na presença/ausência das espécies observadas. Para comparar os índices de diversidade taxonômica entre os períodos utilizou-se o teste-T ( $p$ $<0.05)$, seguindo todas as premissas do teste. Durante todo período de estudo foram coletadas 11 espécies pertencentes a duas famílias de ermitões (Diogenidae e Paguridae), no primeiro período foram encontradas 416 indivíduos (10 espécies), já no segundo 1776 indivíduos foram coletadas (sete espécies. Seis espécies foram comuns para ambos os períodos. $\mathrm{O}$ índice $\mathrm{H}^{\prime}$ teve média e desvio padrão de $0.48 \pm 0.44$ durante o primeiro período e $0.61 \pm 0.40$ durante o segundo. Os índices $\Delta$ e $\Delta^{+}$apresentaram respectivamente média e desvio padrão de $37.06 \pm 29.67$ e $78.73 \pm 8.76$ durante o primeiro período e $31.11 \pm 23.78$ e $84.98 \pm 10.31$ durante o segundo. Somente o índice $\Delta^{+}$diferiu entre os períodos amostrados $(p=0.024)$, aumentando do primeiro para o segundo período. Essa alteração ocorreu devido ao fato de que durante o segundo período ermitões da família Paguridae foram coletados com maior frequência, contrastando com o primeiro período, quando essas espécies representaram apenas $3.81 \%$ da abundância nesse período. O aumento dos valores de $\mathrm{H}^{\prime}$ (embora não significativo) pode decorrer da maior abundância de algumas espécies. Já a medida $\Delta$ teve pouca variação entre os períodos, indicando que as informações que o índice considera permaneceram similares. $\mathrm{O}$ índice $\Delta^{+}$ trouxe novas informações que possibilitam uma melhor compreensão da diversidade, por incorporar relações de parentesco (não evidente utilizando $\mathrm{H}^{\prime}$ ), para que as medidas de conservação e manutenção levem em conta a diversidade taxonômica e não somente o número de espécies local.
\end{abstract}

Palavras-chave: distinção taxonômica, padrões de diversidade, ambiente costeiro, Diogenidae, Paguridae. 